\title{
The Different Causes and Management of Chronic Sphenoid Rhinosinusitis
}

\author{
Ali Almomen ${ }^{1 *}$, Abdullah A AlShakhs ${ }^{2}$, Ali AlTuraifi' ${ }^{2}$, Njood Alaboud ${ }^{2}$ and Mousa Alshehri \\ ${ }^{1}$ Consultant Rhinology \& Skull base surgery, King Fahad Specialist Hospital, Saudi Arabia \\ ${ }^{2}$ Medical intern, Saudi Program, Saudi Arabia
}

Submission: March 03, 2020; Published: March 30, 2020

*Corresponding author: Ali Almomen, Consultant Rhinology \& skull base surgery, King Fahad Specialist Hospital Dammam, Kingdom of Saudi Arabia

\section{Abstract}

Background: Chronic sphenoid rhinosinusitis (CSRS) is a rare clinical condition reported only in 1-3\% cases of paranasal sinus disease. The most common symptoms of CSRS were headache, ophthalmological and nasal symptoms. Even though CSRS is rare, it's very significant clinically due to its undetectable anatomical location, ambiguous symptoms and the complications associated with it.

Objective: To present the different clinical manifestations, diagnostic, and management strategies of chronic sphenoid rhinosinusitis in order to prevent delayed diagnosis and providing early management.

Method: This is a retrospective clinical study, which was conducted between January 2008 to November 2019. This study was conducted in the ENT department of King Fahad specialist Hospital in Saudi Arabia. It included only the patients with sole involvement of chronic rhinosinusitis.

Conclusions: CSRS is difficult to diagnose and treat due to ambiguous and vague clinical features. CSRS most common symptoms are headache, visual loss, and nasal obstruction. The cornerstone of radiological diagnosis of CSRS is CT scan. Endoscopic sinus surgery is the gold standard of the surgical treatment for CSRS.

keywords: Sphenoid Sinus; Fungal Ball; Allergic Fungal Sinusitis; Endoscopy; Allergic Fungal Rhinos inusitis Bacterial Sphenoid Sinusitis; Mucocele; Mucopyocele

Abbreviation: CSRS: Chronic Sphenoid Rhino sinusitis; SAFRS: Sphenoid Allergic Fungal Rhino sinusitis; ISFB: Isolated Sphenoid Fungal Ball; FB: Fungal ball; AFRS: Allergic Fungal Rhino sinusitis

\section{Introduction}

Chronic sphenoid rhinosinusitis (CSRS) is defined as a spectrum of either inflammatory or infective diseases occurring exclusively in sphenoid sinus which last for at least 12 weeks without complete resolution [1]. This may include fungal rhinosinusitis, bacterial rhinosinusitis, and mucocele. The pneumatization of sphenoid sinuses usually start at the age of 6 years and is completed by the 9th to 12 years [2]. Up to date, the youngest known patient who diagnosed with sphenoiditis was 10 years old [3]. There are several important structures adjacent to sphenoid sinus which vulnerable to injury through any sphenoid sinus lesion, including the pituitary gland, optic nerve and chiasm, middle cranial fossa, internal carotid artery, cavernous sinus, the dura, pterygoid canal and nerve and cranial nerve III, IV, V1, V2, and VI $[4,5]$. Even though isolated sphenoid sinus lesion is rare, it's very significant clinically due to its undetectable anatomical location, ambiguous symptoms and the complications associated with injury to the above structures [6]. The main focus of this study is to present the different clinical manifestations and diagnostic strategies of CSRS, in order to prevent delayed diagnosis and providing early management. It was conducted at King Fahad Specialist Hospital (KFSHD), Eastern region, Saudi Arabia.

\section{Method}

This is a retrospective clinical study which was conducted in the otolaryngology department of King Fahad specialist Hospital, Dammam, Saudi Arabia, from January 2008 to November 2019. The clinical features, radiological images, operative findings, and clinical outcomes were retrospectively reviewed and analysed with full description of some selected cases are presented in this report. Patients included were: 1-isolated sphenoid chronic rhinosinusitis which were confirmed by computed tomography (CT) and/or magnetic resonance imaging (MRI); 2- intraoperative 
evidence of chronic rhinosinusitis within the sphenoid sinus. This study was reviewed and approved by the institutional review board (IRB) at our institution.

\section{Result}

A diagnosis of isolated sphenoid bacterial sinusitis (40\%), fungal ball (23.3\%), allergic fungal rhinosinusitis (23.3\%), Mucocele and mucopyocele (13.3\%), had been made in 30 patients with the age ranging between 14-50 years old. The most common symptoms were headache followed by nasal and ophthalmological symptoms. Even though CT scan was the most important tool in the diagnosis, the conformation of the diagnosis was made either intraoperatively or by cultures. Endoscopic sinus surgery was the standard care of management [Table 1].

\section{Discussion}

\section{Bacterial Sphenoid Rhinosinusitis}

In this study, bacterial sphenoid rhinosinusitis (BSRS) was

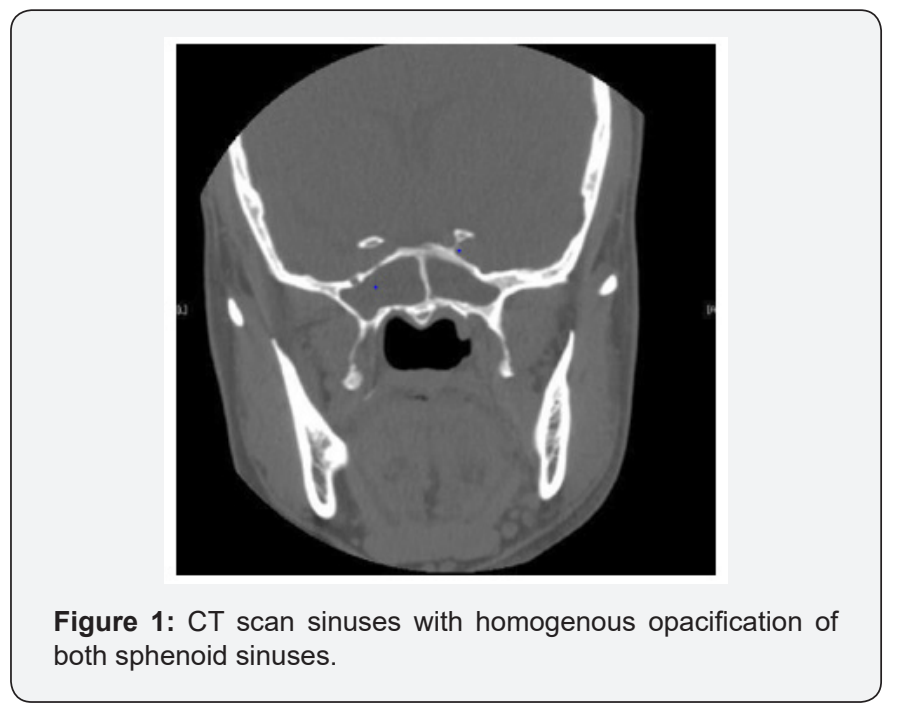

the most common sphenoid inflammatory disease, occurring in 12 out of 30 patients. The commonest isolated pathogens were Staphylococcus aureus, anaerobes and aerobic gram-negative Bacilli [7-10]. The majority of patients presented with headache, which was not specific in site, quality, as well as intensity. Other important features were blurred vision, nasal obstruction, and rhinorrhea [11]. Physical examination and endoscopic finding of cases may show polypoid tissue in the sphenoethmoidal recess, Edema of the sphenoethmoidal recess mucosa and mucopurulent secretion at the sphenoethmoidal area. In most cases CT imaging was the key to proper diagnosis. In BSRS CT scan may demonstrate abnormal findings of partial or complete opacification, changes in air-fluid level and mucosal thickening (Figure 1). Management of patients with BSRS is mainly medical with antibiotic based on culture and sensitivity in addition to corticosteroid and topical decongestant. The only patients who failed to respond to medical treatment or presented with complications, were managed surgically with endoscopic sphenoidotomy (Figure 2).

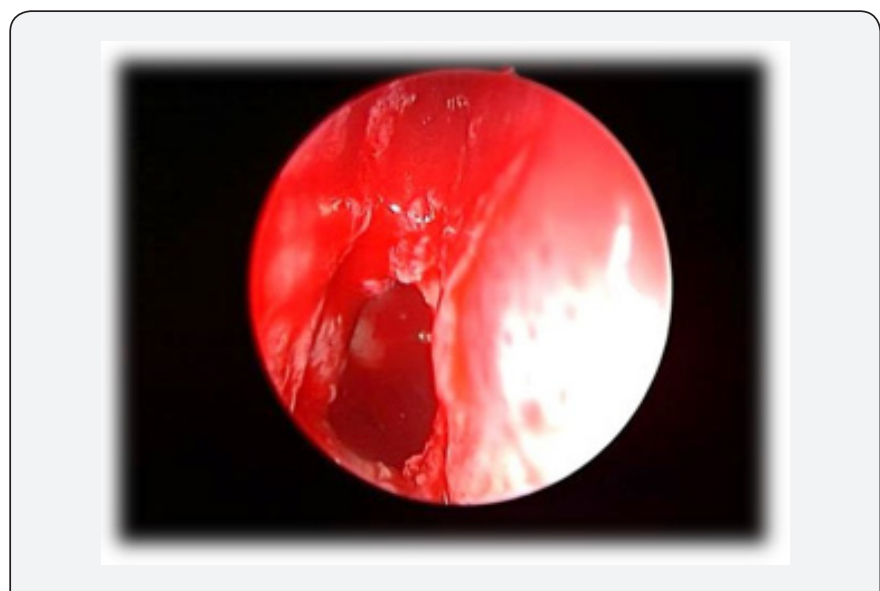

Figure 2: Endoscopic sphenoidotomy for bacterial sphenoid sinusitis.

Table 1: A diagnosis made in 30 patients with the age ranging between $14-50$ years old.

\begin{tabular}{|c|c|c|}
\hline Pathologies of Isolated Sphenoid Inflammatory Disease & Number of Cases & Percentage (\%) \\
\hline Bacterial sphenoid sinusitis (acute/chronic) & 12 & $40 \%$ \\
\hline Allergic fungal sinusitis (AFS) & 7 & $23.30 \%$ \\
\hline Fungal ball & 7 & $23.30 \%$ \\
\hline Mucocele, mucopyocele & 4 & $13.30 \%$ \\
\hline Total & 30 & 100 \\
\hline
\end{tabular}




\section{Global Journal of Otolaryngology}

\section{Allergic Fungal Sinusitis}

AFRS is an immunological reaction to fungal antigen rather than a fungal infection. This commonly results in mucosal thickening and marked bone resorption as a result of the secretion of enzymes. Additionally, a thick mucin may cause bony decalcification. Interestingly, it is common in immunocompetent younger patient with atopic background. Sphenoid allergic fungal rhinosinusitis (SAFRS) was reported in 7 out of 30 patients in our study. The clinical presentation of (SAFRS) is often nonspecific and vague; thus, diagnosis may be delayed in many cases [12]. Up to date, headache refractory to the medical management is the most common symptom of isolated sphenoid sinus lesion; it presents in 70 to $90 \%$ of patients $[13,14]$. In this series, the most presenting feature was headache followed by nasal discharge. History and physical examination have little benefit in establishing the correct diagnosis. Imaging studies (CT scanning and/or MRI) and Nasal endoscopy are essential for a thorough evaluation and management $[15,16]$.
All patient did CT scan which provided valuable information regarding the diagnosis of SAFRS and its relation to bony erosion. CT findings of SAFRS may present with heterogeneous hyperdensities that are often unilateral and asymmetric as shown in one of our cases (Figure 3). SAFRS can easily compress the cranial nerves. It had been documented that cranial neuropathies occur in $10 \%$ of cases of SAFRS with bone erosion [17]. Endoscopic surgery has become the fundamental approach for SAFRS. It's includes surgical debridement of fungal material in order to open and ventilate the sinuses (Figure 4), and post-operative steroid to control the recurrence. There are few reports about complication of ISAFRS. Actually, the main complication of allergic comes after sphenoid sinus involvement. The main complications are visual disturbances, diplopia and cavernous sinus thrombosis $[18,19]$. We have reported one case in our series with cavernous sinus thrombosis as a complication of isolated sphenoid allergic fungal sinusitis. Left sphenoidotomy was done and she was treated with Meropenem, Vancomycin, Amphotericin B and Enoxaparin and improved.

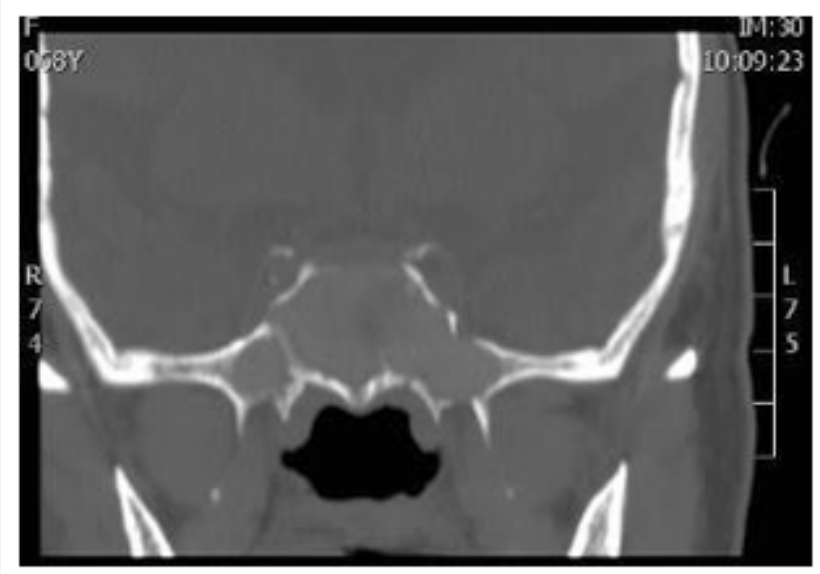

Figure 3: A computed tomography (CT) scan, coronal view showing a heterogeneous opacity filling the sphenoid sinus.

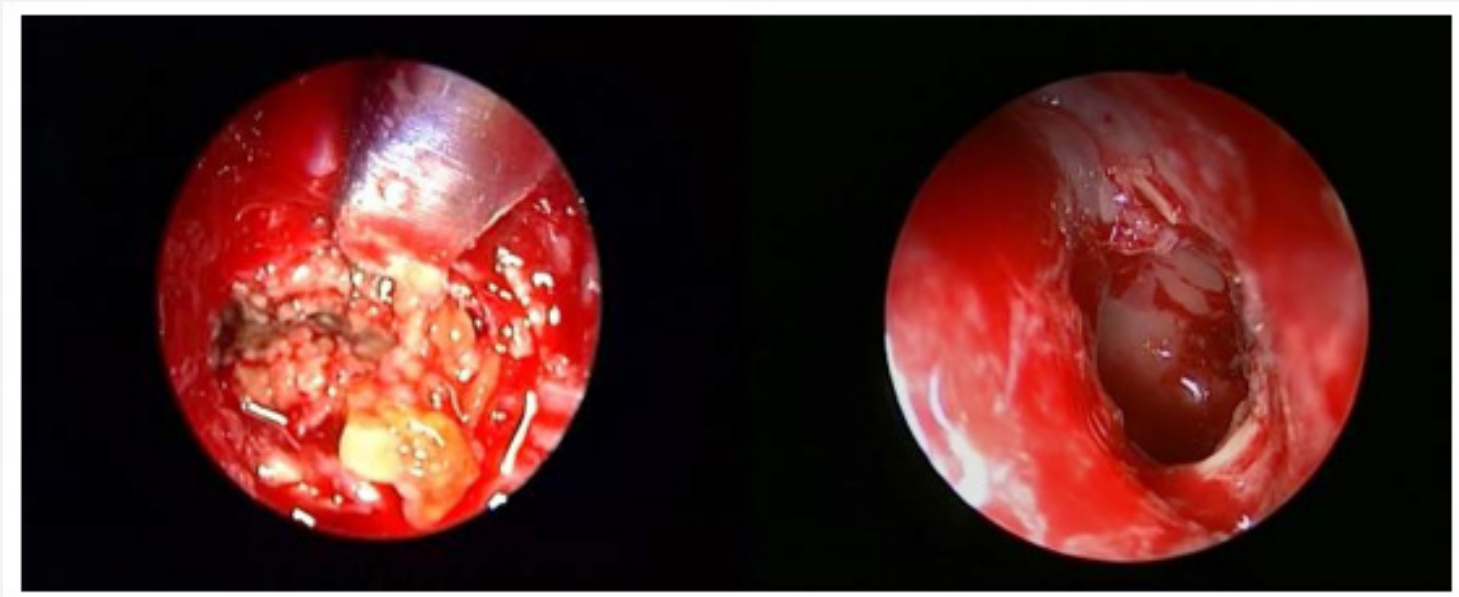

Figure 4: (A) Intraoperative endoscopic view of the allergic mucin and fungal mud filling the sphenoid sinus. (B) Endoscopic view of the Post-operative wide sphenoidotomy procedure. 


\section{Global Journal of Otolaryngology}

\section{Fungal Ball}

Fungal ball (FB) is an accumulation of dense fungal hyphae, most commonly in the maxillary sinus, with only $10 \%$ of the cases in sphenoid sinus [4]. Isolated sphenoid fungal ball (ISFB) was reported in 7 out of 30 patients in our study. The exact mechanism of spread of fungal infection only to sphenoid sinus is unknown. It has been hypothesized that ostial closure creates an anaerobic environment favourable for growth of Aspergillus, or that chronic sinusitis predisposes to the development of FB [5]. Headache refractory to the medical management is the most common symptom of ISFB $[13,14]$. In our study, the most presenting feature was post-nasal discharge followed by headache and rarely cough. History and physical examination have little benefit in establishing the correct diagnosis. Imaging studies (CT scanning and/or MRI) and Nasal endoscopy are essential for a thorough evaluation and management $[15,16]$. Figure 5 shows, fungal ball appears as hyper-attenuating in CT due to dense hyphae with evidence of thickening of the wall of the paranasal sinuses and chronic inflammation with sclerosis. MRI should only provide for patient with suspicion of invasion to surrounding structures [20].

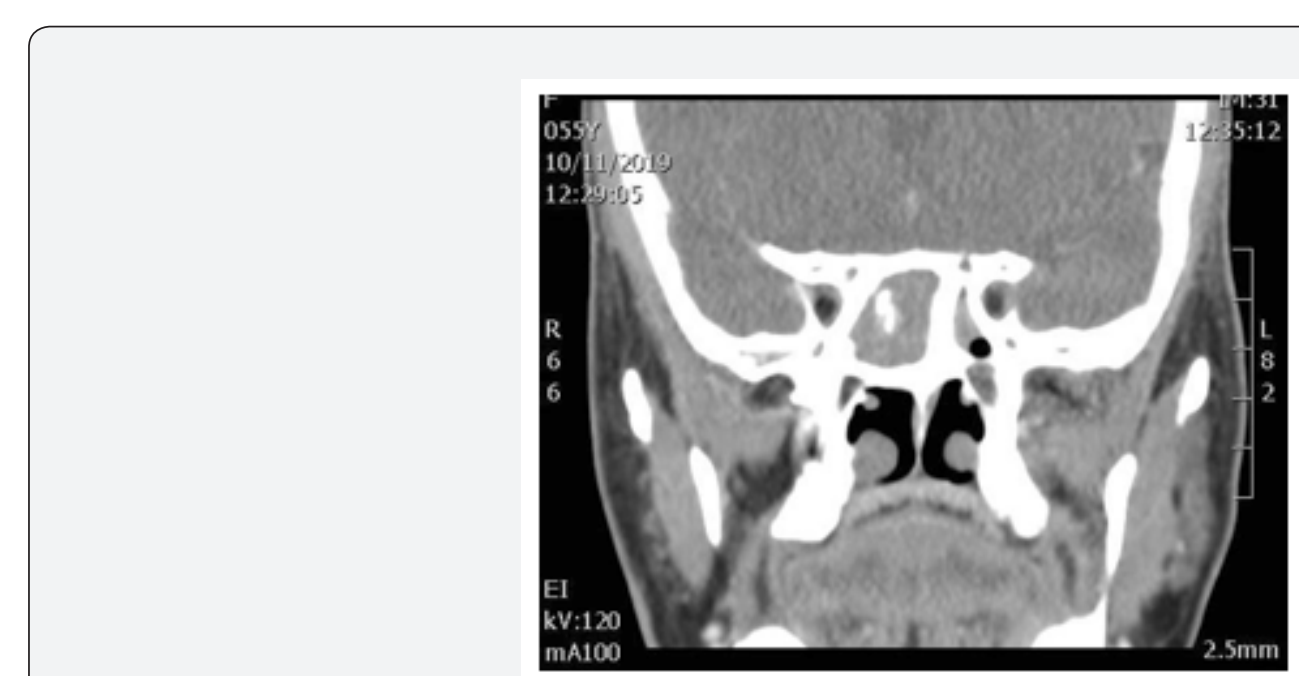

Figure 5: A computed tomography (CT) scan, coronal view of the paranasal sinuses, showing a hyper dense opacity filling the sphenoid sinus.

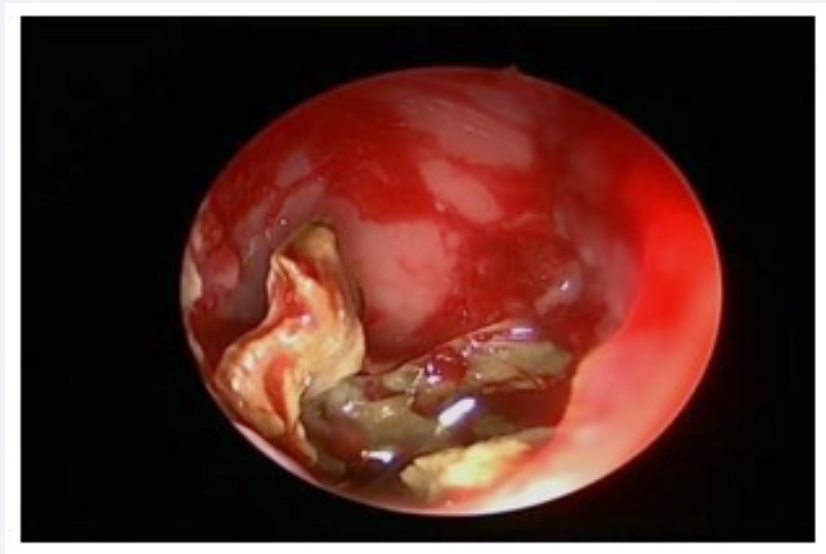

Figure 6: Endoscopic intraoperative view of the sphenoid sinus after sphenoidotomy showing fungal material inside sinus cavity.

On Nasal endoscopy the most common findings are bone thickening or sclerosis of sinus walls (Figure 6). This can be secondary to the inflammatory process associated with the fungal ball and is often reversible after removing it [5,12]. Microbiology confirms fungal infection and eventually identifies fungal species. The microscopic appearance of Aspergillus on direct smear is that of a conidiophore [21]. On culture, the most frequently isolated fungus is Aspergillus fumigates. One of our fungal ball cases 


\section{Global Journal of Otolaryngology}

showed Aspergillus but the remaining 6 cases had -ve culture. The surgical management of sphenoid sinus include both endoscopic and open techniques. However, endoscopic surgery has become the fundamental approach for sphenoid sinus lesions. It can be proceeded in a trans-ethmoidal fashion or through the anterior sphenoid sinus wall directly at the site of the natural ostium [22]. No post-operative medical treatment was necessary for all patients. Post-operative follows up was done for all patient with no complication and recurrence.

\section{Mucocele}

Mucoceles are benign, encapsulated lesions filled with mucus and lined by epithelium. They are expansile and locally destructive with the ability to resorb bone, causing erosions of the bony walls of the sinus [23].

Thinning, distension and erosion of the sinus bony walls happens because of the retained mucoid secretion within the sinus. Our study has identified 4 out of 30 patients with mucocele. The clinical features of sphenoid sinuses mucocele includes headache, diplopia, external ophthalmologist and visual disturbances due to involvement of optic or oculomotor, trochlear and abducent nerves.

CT scan is the main tool for diagnosis of sphenoid sinus mucocele [23]. Figure 7 shows CT scan findings of one of our cases. MRI scan of one of our cases (Figure 8) shows a low signal on T1 and a high signal on T2. Regarding treatment, asymptomatic mucocele, could be left without any surgical intervention. However, surgical intervention is recommended in symptomatic, or complicated cases. Endoscopic trans-nasal image-guided sphenoidotomy has become the fundamental treatment approach, as illustrated in Figure 9. The purpose of surgery is to allow adequate drainage and to avoid recurrences of the condition (Figure 10). Marsupialization is another option in the management of mucocele.

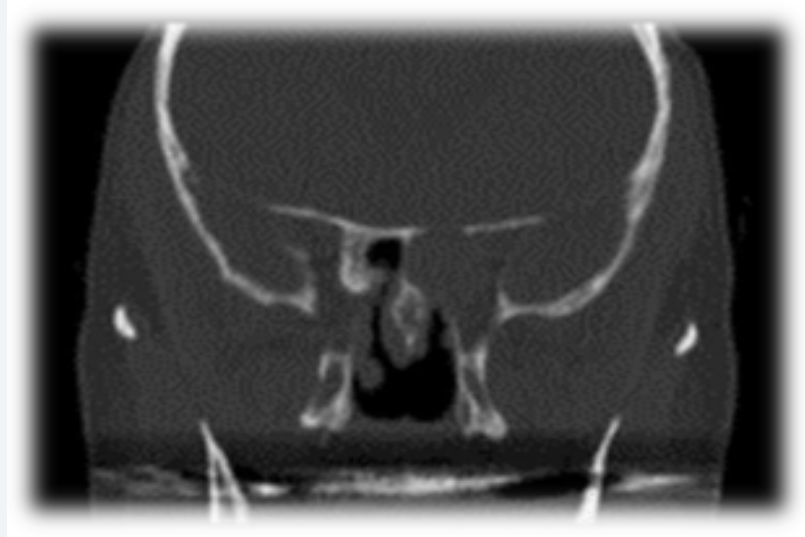

Figure 7: CT scan left sphenoidmucocele.

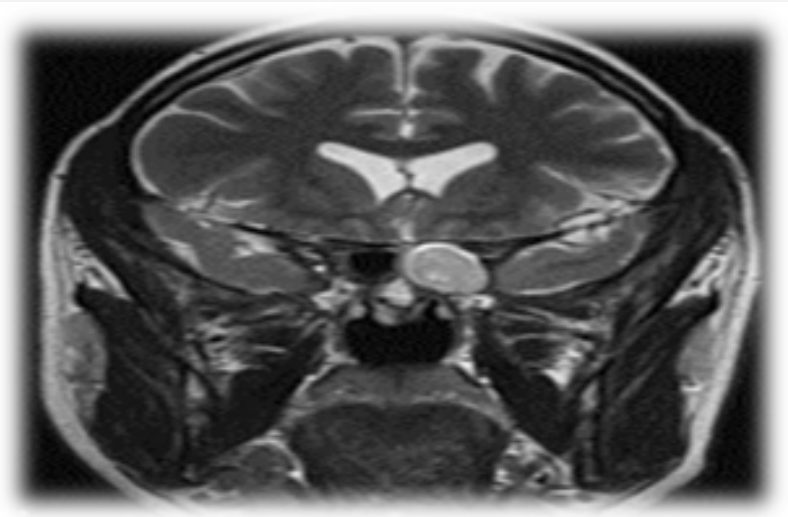

Figure 8: MRI left sphenoid mucocele. 


\section{Global Journal of Otolaryngology}

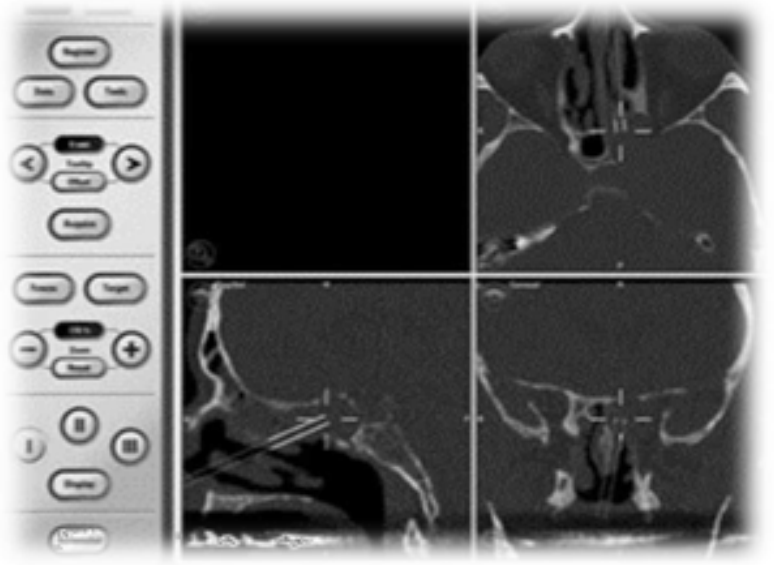

Figure 9: Image-guided surgery IGS.

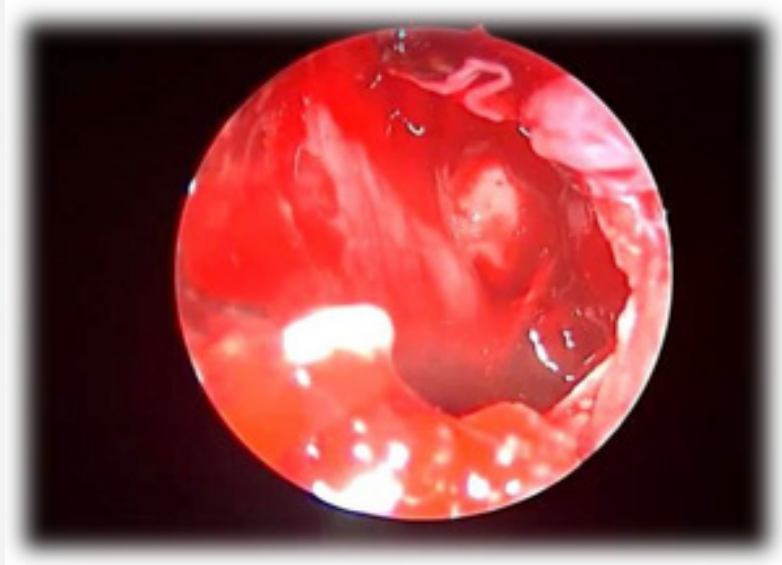

Figure 10: Wide sphenoidotomy (Image guided endoscopic surgery for marsupialization of left sphenoid mucocele).

\section{Conclusion}

Even though chronic sphenoid rhinosinusitis is rare, it's clinically important because untreated CSRS can cause significant orbital and intracranial complications due to the vital structures near the sphenoid sinuses. The clinical features of CSRS are ambiguous which make its diagnosis more difficult. Headache refractory to the medical management and post-nasal discharge is the most common symptom of CSRS. CT scan is still the cornerstone of radiological diagnosis of CSRS. Endoscopic sinus surgery is the standard care of management. Post-operatively, the majority of patient had good results with no complication and recurrence.

\section{Consent}

Written informed consent was obtained from the parents for publication of this case report on behalf of the patient.

\section{References}

1. Fokkens WJ, Lund VJ, Mullol J, et al. (2012) EPOS 2012: European position paper on rhinosinusitis and nasal polyps 2012. Rhinology 50(1): 1-12.

2. Som PM, Lawson W, Fatterpekar GM, Zinreich SJ (2011) Embryology, anatomy, physiology, and imaging of the sinonasal cavities. In: Som PM, Curtin HD, Head and Neck Imaging. $5^{\text {th }}$ ed, St Louis: Elsevier Health Sciences P: 102-165.

3. Nour YA, Al Madani A, El Daly A, Gaafar A (2008) Isolated sphenoid sinus pathology: spectrum of diagnostic and treatment modalities. Auris Nasus Larynx 35(4): 500-508.

4. Grosjean P, Weber R (2007) Fungus balls of the paranasal sinuses: a review. Eur Arch Otorhinolaryngol 264: 461-470.

5. Chakrabarti A, Denning DW, Ferguson BJ, Ponikau J, Buzina W, et al. (2009) Fungal rhinosinusitis: a categorization and definitional schema addressing current controversies. Laryngoscope 119: 1809-1818.

6. Sethi DS (1999) Isolated sphenoid lesions: diagnosis and management. Otolaryngol Head Neck Surg 120: 730-736. 
7. Lew D, Southwick FS, Montgomery WW, Weber AL, Baker AS (1983) Sphenoid sinusitis. A review of 30 cases. N Eng J Med 309(19): 11491154 .

8. Friedman A, Batra PS, Fakhri S, Citardi MJ, Lanza DC (2005) Isolated sphenoid sinus disease: Etiology and management. Otolaryngol Head Neck Surg 133(4): 544-550.

9. Socher JA, Cassano M, Filheiro CA, Cassano P, Felippu A (2008) Diagnosis and treatment of isolated sphenoid sinus disease: a review of 109 cases. ActaOtolaryngol 28(9): 1004-1010.

10. Brook I (2002) Bacteriology of acute and chronic sphenoid sinusitis. Ann Otol Rhinol Laryngol 111(11): 1002-1004.

11. Ruoppi P, Seppä J, Pukkila M, Nuutinen J (2000) Isolated sphenoid sinus diseases: report of 39 cases. Arch Otolaryngol Head Neck Surg 126(6): 777-781.

12. Cakmak O, Shohet MR, Kern EB (2000) Isolated sphenoid sinus lesions. Am J Rhinol 14: 13-19.

13. Wyllie JW, Kern EB, Djalilian M (1973) Isolated sphenoid sinus lesions. Laryngoscope 83: 1252-1265.

14. Martin TJ, Smith TL, Smith MM, Loehrl TA (2002) Evaluation and surgical management of isolated sphenoid sinus disease. Arch Otolaryngol 128: 1413-1419.

15. Lawson W, Reino A (1997) Isolated sphenoid sinus disease: an analysis of 132 cases. Laryngoscope 107: 1590-1595.
16. Wang ZM, Kanoh N, Dai CF, et al. (2002) Isolated sphenoid sinus disease: an analysis of 122 cases. Ann Otol Rhinol Laryngol 111: 323327.

17. Illing EA, Dunlap Q Woodworth BA (2015) Outcomes of pressureinduced cranial neuropathies from allergic fungal rhinosinusitis. Otolaryngol Head Neck Surg 152(3): 541-545.

18. Veress B, Malik OA, El Tayeb AA, El Daoud S, Mahgoub ES (1973) Further observations on the primary paranasal aspergillus granulomas in Sudan: a morphological study of 46 cases. Am J Trop Med Hyg 22: 765-772.

19. Bent JP 3rd, Kuhn FA (1994) Diagnosis of allergic fungal sinusitis. Otolaryngol Head Neck Surg 111(5): 580-588.

20. Lee LA, Huang CC, Lee TJ (2004) Prolonged Visual Disturbance Secondary to Isolated Sphenoid Sinus Disease. Laryngoscope 114: 986-990.

21. Bardana EJ Jr (1981) The clinical spectrum of aspergillosis-part 2: classification and description of saprophytic, allergic, and invasive variants of human disease. Crit Rev Clin Lab Sci 13: 85-159.

22. Metson R, Gliklich RE (1996) Endoscopic treatment of sphenoid sinusitis. Otolaryngol Head Neck Surg 114: 736-744.

23. Soon SR, Lim CM, Singh H, Sethi DS (2010) Sphenoid sinus mucocele: 10 cases and literature review. J Laryngol Otol 124(1): 44-47.

\section{Your next submission with Juniper Publishers will reach you the below assets}

- Quality Editorial service

- Swift Peer Review

- Reprints availability

- E-prints Service

- Manuscript Podcast for convenient understanding

- Global attainment for your research

- Manuscript accessibility in different formats

( Pdf, E-pub, Full Text, Audio)

- Unceasing customer service

Track the below URL for one-step submission https://juniperpublishers.com/online-submission.php 